\title{
Intermediate Frequency Spot Welding Performance Investigation of Precision Ultra-high Strength Quenching Steel Plate
}

\author{
Z. W. GU, ${ }^{11}$ Z. L. ZHANG, ${ }^{11}$ L. J. HAN ${ }^{2)}$ and H. $X U^{11}$ \\ 1) The Department of Materials Science and Engineering, Jilin University, Nanling Campus, No. 142 Renmin Street, \\ Changchun 130025, P. R. China. E-mail: zzl.8691@163.com $\quad$ 2) The FAW-Wolkswagen Automobile Company Ltd., No. 5,
} Anqing Road, Dongfeng Street, Changchun 130042, P. R. China.

(Received on December 3, 2008; accepted on May 12, 2009)

\begin{abstract}
In recent years the precision ultra-high strength quenching steel plates (PUHSQS) have been widely used in the automobile production to reduce weight and improve passive safety. This paper investigates the spot welding performance of PUHSQS EN 1029TL4225, a kind of advanced high strength steel, whose tension strength can attain $1500 \mathrm{MPa}$ after being quenched. Using the intermediate frequency (IF) spot welding process, two kinds of welded joints are made: the joint of two PUHSOS plates and the joint between PUHSQS EN 10292TL4225 and the micro-alloy steel H340 LAD. The mechanical performances of welded joints, such as the tension strength, the hardness distribution, are tested. Besides, the macrostructure and microstructure are also analyzed. From the results, we can see that both of two kinds of welded joints have perfect properties and internal quality, and also the mechanical performances meet the actual production requirement completely. So we conclude that the steel EN 10292 TL4225 has good spot welding performance.
\end{abstract}

KEY WORDS: precision ultra-high strength steel sheet; IF spot welding; EN 10292 TL4225.

\section{Introduction}

To decrease the fuel consumption and environmental pollution, the weight reduction is intensively required in automobile industry. With the application of aluminium and magnesium materials the weight can be reduced obviously. However, their high cost and lower strength and small formability become the problems. The high strength steel represents a better solution because it can increase the strength-to-mass ratio of sheet components. ${ }^{1-3)}$ Using PUHSQS the thickness or the cross section dimensions of the part is reduced, then the weight reduction in many automobile components or structural members is achieved. Moreover, its mechanical properties can dramatically improve collision safety performance. In recent years, the application of PUHSQS has been increasing rapidly.

In the application of PUHSQS, one of the most important steps is the spot welding jointing between high strength steel stamping parts and others of body in white (BIW). To make a car body have a better performance, high strength steels should possess good spot welding performance because only by that other parts can be connected with them firmly. With the special physical and chemical properties, PUHSQS represents many characteristics different from other conventional automobile steels in the spot welding performance. So the investigation of the spot welding performance of PUHSQS is very necessary. In this paper the spot welding performance of PUHSQS EN 10292TL4225 is investigated. The IF spot welding process is adopted to make two different kinds of welded joints, that is, the joints between the two EN 10 292TL4225 steel plates and the joints between the EN 10292 TL4225 and H340 LAD steel plates. The mechanical performances and hardness distribution of the welded joints are tested, and the macrostructure and microstructure of the welded joints are analyzed and compared. From the results, we can see that both of two kinds of welded joints have perfect properties and internal quality, and also the mechanical performances meet the actual production requirement completely. So we conclude that the EN 10292 TL4225 steel has good spot welding performance.

\section{Experimental Research}

\subsection{Materials Preparation}

In the experiment, two kinds of materials are used. One is PUHSQS EN 10292TL4225, and the other is micro-alloy steel plate H340 LAD. The former is a kind of boron alloy steel, which is an advanced high strength steel with the performance of press hardening. It is generally used to make automobile stamping parts in the hot stamping process. The boron alloy steel blank is firstly heated to $900-950^{\circ} \mathrm{C}$ to be austenited in a furnace, then transferred to a forming tool with internal cooling tunnels, where it is cooled and quenched by the die surfaces. Finally, the microstructure of the part is transformed into martensite from austenite. So the tension strength can be improved greatly. At the beginning, the tension strength of the steel is about 500-600 
Table 1. The chemical composition of EN 10292 TL4225.

\begin{tabular}{l|l|l|l|l|l|l|l|l|l|l|l|l}
\hline EN 10292 TL4225 & $\mathrm{C}$ & $\mathrm{Mn}$ & $\mathrm{Si}$ & $\mathrm{P}$ & $\mathrm{S}$ & $\mathrm{Al}$ total & $\mathrm{Ti}$ & $\mathrm{Cr}$ & $\mathrm{B}$ & $\mathrm{Mo}$ & $\mathrm{Cu}$ & $\mathrm{Ni}$ \\
\hline Min. & 0.22 & 1.20 & 0.2 & -- & -- & 0.02 & 0.02 & 0.11 & 0.002 & - & - & - \\
\hline Max. & 0.25 & 1.40 & 0.3 & 0.02 & 0.005 & 0.05 & 0.05 & 0.20 & 0.0035 & 0.10 & 0.10 & 0.10 \\
\hline
\end{tabular}

Table 2. The chemical composition of H340 LAD.

\begin{tabular}{l|l|l|l|l|l|l|l}
\hline $\mathrm{C}$ & $\mathrm{Si}$ & $\mathrm{Mn}$ & $\mathrm{P}$ & $\mathrm{S}$ & $\mathrm{Al}$ & $\mathrm{Tib}$ & $\mathrm{Nbb}$ \\
\hline 0.10 & 0.50 & 1.00 & 0.025 & 0.025 & 0.015 & 0.15 & 0.09 \\
\hline
\end{tabular}

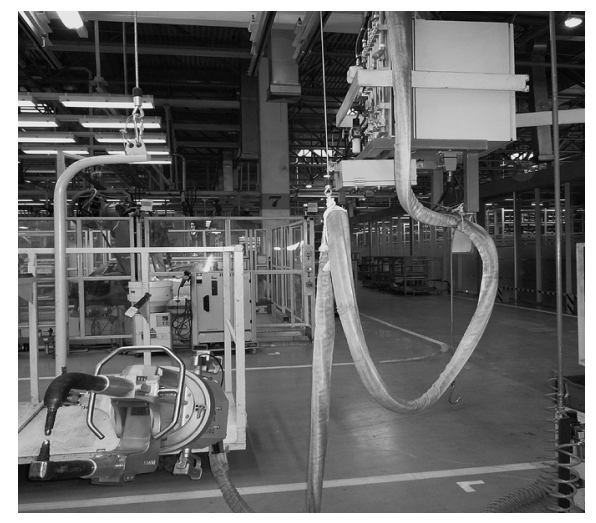

Fig. 1. The IF spot welding machine used in the experiment.

$\mathrm{MPa}$, but after the process the strength can attain 1500 MPa. ${ }^{4-8)}$ The main chemical composition of the PUHSQS EN 10292TL4225 is shown in Table 1. Its thickness is $1.8 \mathrm{~mm}$. The other is a kind of common micro-alloy steel plate. Its thickness is $1.0 \mathrm{~mm}$ and its main chemical composition is shown in Table 2.

\subsection{IF Spot Welding Equipment}

In this experiment the IF spot welding process is used and the IF spot welding machine (NSC60HA040.02) shown in Fig. 1 is applied whose power system wiring principle is shown in Fig. 2. Applying DC is the most prominent technical character of IF spot welding. From Fig. 2, we can see that DC is used in IF inverter welding. By using DC, there is no inductance and impact on peak value, and the power supply system is almost no impact on the inverter system. Also the welding process can be more stable and there is no impact from the shape and the material of work-piece. The adjustment accuracy and surveillance precision of DC system are 20 times higher than $\mathrm{AC}$ system, in addition, secondary current can really maintain constant. The Fig. 3 shows the waveform of IF inverter welding. Compared with the conventional spot welding method, the IF spot welding process has the following advantages: (1) Wide welding conditions scope. (2) More precise welding current control system. (3) High stability of the welding process. So it can dramatically decrease the welding defects such as splash etc. This process is thought to be the more proper method for the spot welding connection of high strength steel.

\subsection{IF Spot Welding Test}

The lap joint is adopted in the spot welding. The picture is shown in Fig. 4. To make the spot welding specimen, Two kinds of parent metals (EN 10292TL4225 and H340 LAD) are firstly machined by using wire-cut method under

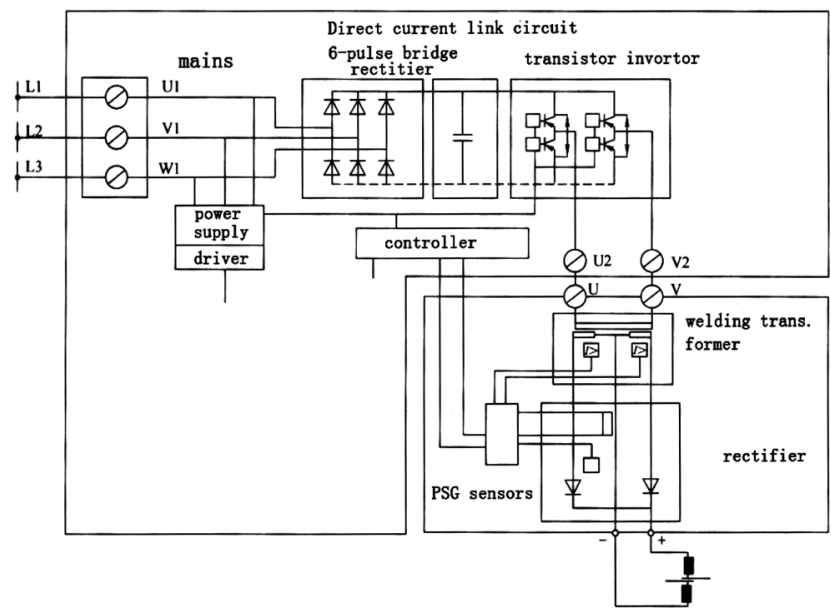

Fig. 2. IF spot welding equipment power system wiring principle.

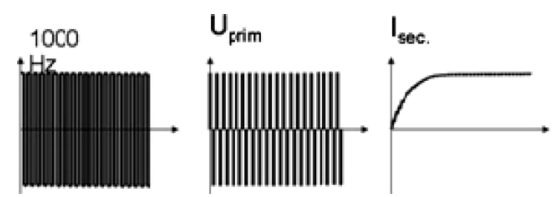

Fig. 3. The waveform of IF inverter welding.
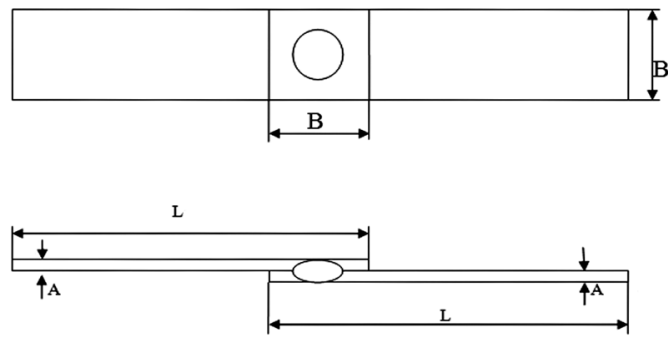

EN 10292 TL4225: $A=1.8 \mathrm{~mm}, \mathrm{H} 340 \mathrm{LAD}: \mathrm{A}=1.0 \mathrm{~mm}$. $\mathrm{B}=25 \mathrm{~mm}, \mathrm{~L}=120 \mathrm{~mm}$.

Fig. 4. The drawings of the spot welding specimen.

the given dimensions, then the IF spot welding method is adopted to finish the two kinds of spot welding specimen: one is the joint between two EN 10292 TL4225 steel plates, and the other is the joint between the steel EN 10292 TL4225 and H340 LAD.

When choosing the welding parameters, the characteristics of ultra high strength quenching steel should be considered carefully. For the original phase of the EN 10292 TL4225 steel plate is martensite, rapid cooling in the welding process will naturally generate a large amount of hard-brittle martensite which will lead to cracks when undergoing a large load. To decrease this harmful hard-brittle microstructure and improve the performances of welded 
Table 3. The IF spot welding process parameters used in the experiment.

\begin{tabular}{c|c|c|c}
\hline Preliminary press time & $600 \mathrm{~ms}$ & Welding current & $7.5 \mathrm{KA}$ \\
\hline Welding time & $350 \mathrm{~ms}$ & Maintain time & $200 \mathrm{~ms}$ \\
\hline Welding pulse number & 2 cycles & Electrode press & $2.5 \mathrm{KN}$ \\
\hline
\end{tabular}

joints, the double pulses are used in the process of welding. The first current pulse is used to weld and the second one is used to temper the welded joints. However, the follows should be noted: (1) The temperature of welded joints should be kept below the martensitic transformations Ms point between the interval of two pulses; (2) The amplitude of the temper current pulse should be chosen appropriately to avoid the temperature of the metal in welded zone higher than that of austenitic phase transformations point. When it exceeds the austenitic transformation temperature, the welded zone metal will be quenched for the second time. At the beginning of the IF spot welding experiment, the size and shape of the electrode, initial electrode press and welding time are firstly determined. Then the welding current is adjusted to obtain the nugget with required dimensions. Then the electrode pressure, the welding time and the welding current are optimized in an appropriate scope, and continue to weld and test until the welded joints completely satisfy the technical requirements. The main process parameters used in the experiment are shown in Table 3.

\section{Analysis of Test Results}

\subsection{Analysis of Tension Test}

As we all know, the most important mechanical property of the welded joint is shear strength. To investigate the shear strength of the two kinds of spot welded joints, onedimension tension testing is carried out on Zwick-Z100 machine. Stretching speed is $10 \mathrm{~mm} / \mathrm{min}$. The testing results show that the average maximal standard load value of the three sets of welded joints between EN 10 292TL4225 and $\mathrm{H} 340 \mathrm{LAD}$ is $3.52 \mathrm{KN}$ and that of same material (EN 10 292TL4225) welded joint is $29.3 \mathrm{KN}$. Under the requirement of the FAW-Wolkswagen factory standard about high strength steel spot welding, both two kinds of welded joints meet the actual need of products. In the tension test, the fracture of different material welded joints occurred at the side of H340 LAD plate. The main reason for this is that the intension strength of the steel H340 LAD is lower than EN 10292 TL4225.

In the tension experiment, both two types of welded joints fracture in the surrounding area of the welded joints and then form a button shape. The fracture zone often appears at the area between the nugget and the heat affected zone. Surrounding the nugget, the columnar dendrite microstructure forms a weak surface which coincides with the high-stress zone of the two blank slots at the lap joint, then a sensitive fracture zone of the welded joint is generated. The fracture zone is located on the bond line and it is easy to form stress concentration due to the tremendous transition of the microstructure in this zone. ${ }^{9)}$ On the other hand, the impurities on the surface of parent metal will form flaws in the fusion-zone, which is detrimental to the frac-

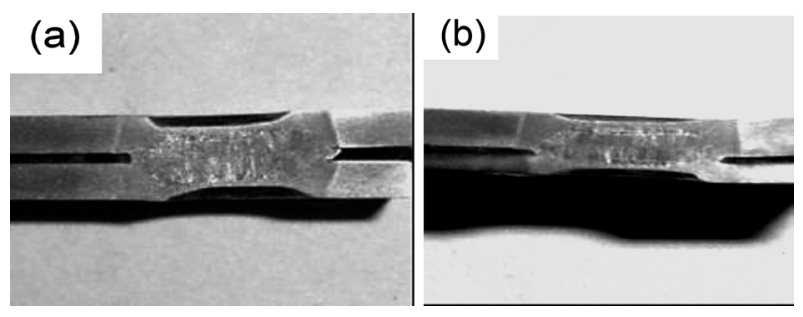

Fig. 5. Macrograph of two kinds of welded joints. (a) Welded joints of two EN 10292 TL4225 steel plates; (b) welding joints between EN 10292 TL4225 and H340 LAD steel plates.

ture strength.

\subsection{Macrostructure Analysis}

The cross sections of the two kinds of welded joints are shown in Fig. 5. It can be seen that there are no internal defects such as crack or shrinkage hole in both of the joints, and the internal quality of the nuggets is perfect. For the same material joints (EN 10 292TL4225), there is no conspicuous boundary between the nugget and the HAZ. On the contrary, for the different material joints (EN 10 292TL4225 and H340 LAD), the boundary between the nugget and HAZ is obvious. The main reason is that the nugget of different material joints has the mixed microstructure composed of martensite and ferrite, which is different from that of the parent metal. Fig. 5(b) also shows that, for the welded joints of different material with different thickness, the nugget has no offset, which ensures the strength of the welded joints.

\subsection{Microstructure Analysis}

The microstructures of the two kinds of welded joints are shown in Fig. 6 (by scanning electron microscopy JSM5310). From Fig. 6(a) and Fig. 6(c), we can see that for the same material welded joints(EN 10 292TL4225), the microstructures of nugget and parent metal are both martensite, and the only difference is that the former grains are a little coarser than those of the latter.

Figure 6(b) shows the nugget microstructure of different material welded joints (EN 10 292TL4225 and H340 LAD). It can be seen that the microstructure is mainly martensite which can greatly enhance the strength, and also some ferrite exist which could enhance the toughness of the welded joints. Figure 6(d) shows the microstructure of H340 LAD parent metal and uniform ferrite constitutes its main microstructure.

\subsection{Analysis of Hardness}

The hardness distribution of the same material weld joints (between EN 10 292TL4225) is investigated. The specimen for hardness testing is shown in Fig. 7(a). It is a piece of circular metal cut around the welding spot including nugget, heat affect zone and parent metal. The radius of the circular metal is about $10 \mathrm{~mm}$. It is polished and corroded by $4 \% \mathrm{HNO}_{3}$ alcohol solution. In the Rockwell Hardness test, the hardness of six selected points shown in Fig. 7(a) are tested. The hardness distribution curve is shown in Fig. 7(b). In the plastic ring region, we can find that the Rockwell Hardness value of the welded joints is 


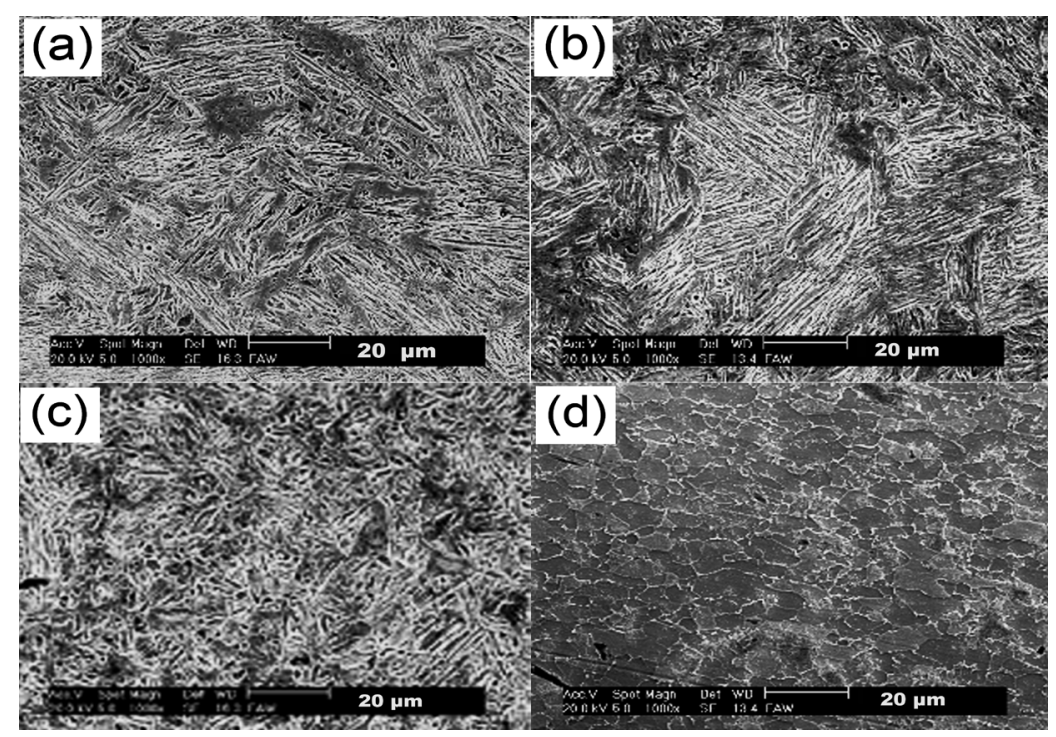

Fig. 6. The SEM micrographs of two kinds of welded joints and their parent metals. (a) The nugget of spot welding between two EN 10292 TL4225 steel plates; (b) the nugget of spot welding between EN 10292 TL4225 and H340 LAD; (c) the microstructure of EN 10292 TL4225 parent metal; (d) the microstructure of H340 LAD parent metal.

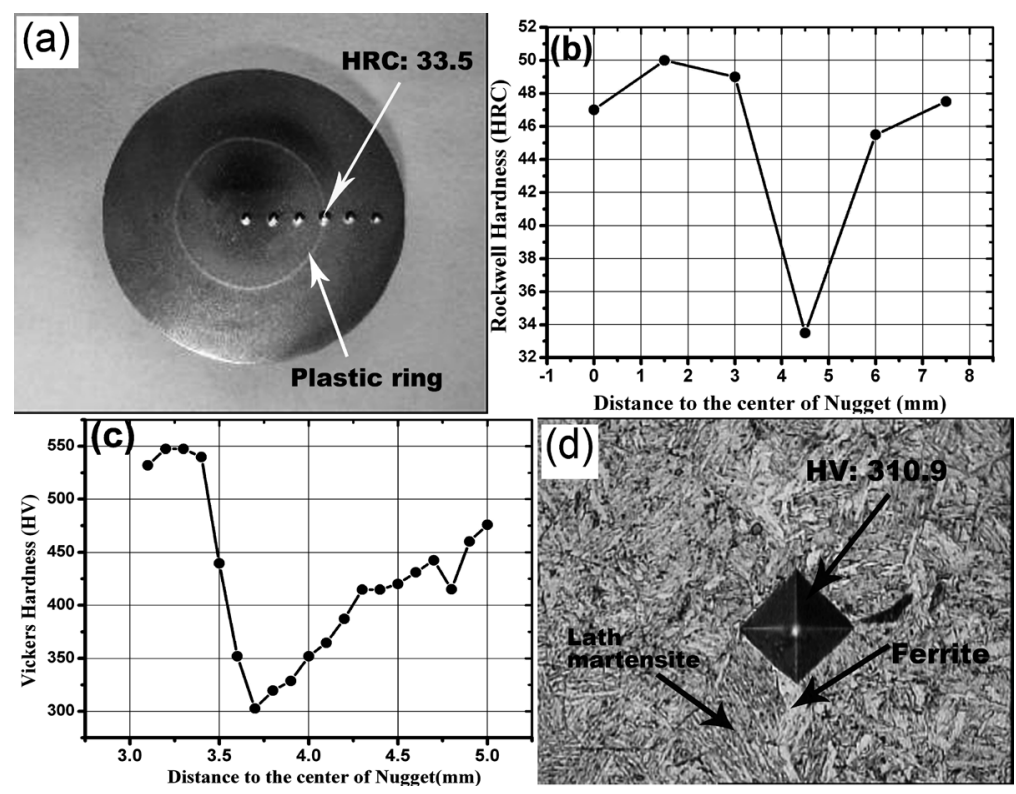

Fig. 7. Hardness distribution test. (a) Test piece of same material welded joint; (b) Rockwell hardness test curve; (c) Vickers hardness test curve; (d) Microstructure at the region of plastic ring. $400 \times$.

significant low (HRC: 33.5). Therefore, we conclude that the microstructure certainly must have changed in the plastic ring region. Then the Vickers Hardness at this region is tested. There are twenty selected points, starting from the position $3 \mathrm{~mm}$ away from the center of nugget, and arranged in order in the direction away from the center of nugget with $0.1 \mathrm{~mm}$ spacing between each two points. Then we get the Vickers Hardness number of each point, and the curve is shown in Fig. 7(c). Figure 7(d) shows the microstructure of the zone with the lowest hardness. It is hybrid microstructure which consists of ferrite and lath martensite, and a large number of ferrite lead to a very low hardness in this zone. Double-pulse spot welding method as above-mentioned is adopted in IF spot welding process. The second pulse is used to temper the welded joints and the temper temperature is about $300-500^{\circ} \mathrm{C}$. Recovery and re-crystallization occur in this temper process. Recovery occurs when the temper temperature reach to about $400^{\circ} \mathrm{C}$. In this process, some of the stored internal strain energy in $\alpha$ solid solution is relieved by virtue of dislocation motion, which effectively reduce the residual stress. With the temper temperature going up, the re-crystallization of $\alpha$ solid solution occurs. The acicular $\alpha$ solid solution disappear and ferrite appear. As the proportion of lath martensite increase in both sides of the plastic ring, the hardness gradually increases, as shown in Fig. 7(c).

As we know, the hardness of nugget is generally lower than parent metal, but the hardness of same material (EN 10 292TL4225) weld joints is slightly higher than parent metal, as shown in Fig. 7(c). Figure 8 shows the transition microstructure of same material weld joints. It can be seen that the microstructures of the nugget and the parent metal 


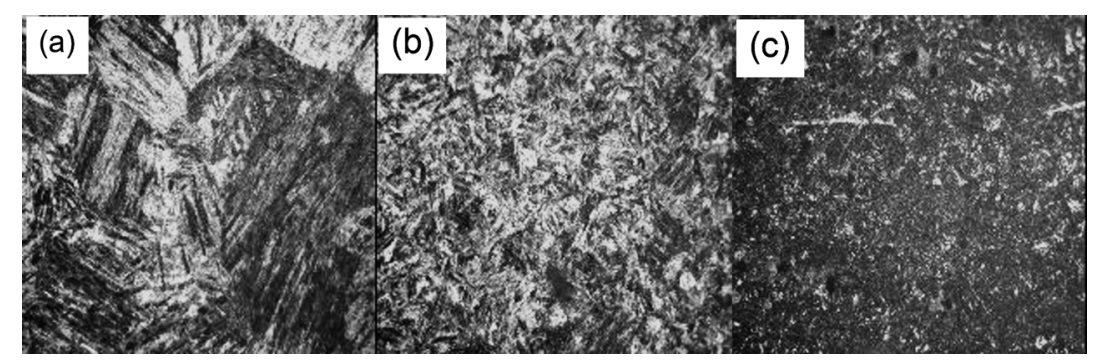

Fig. 8. Microstructures of the welded joint of EN 10 292TL4225. (a) Nugget; (b) HAZ; (c) parent metal. 400×.

are both martensite, and the only difference is that the grain of the nugget more coarser than that of the original material. Then we conclude that the coarser lath martensite lead to the higher hardness in the nugget.

\subsection{Analysis of Fracture Visage}

Figure 9(a) shows the fracture visage of H340 LAD parent metal. It is a typical dimple fracture. So the material has perfect plasticity. Comparing Fig. 9(a) with Fig. 9(b), we can see that the size of equiaxed dimples in the microstructure of H340 LAD parent metal is more uniform than that of EN 10292TL4225, and the equiaxed dimples in the microstructure of H340 LAD parent metal have bigger depth, which can absorb more energy during fracture process. Fracture deformation makes the wall of dimples into a sharp thin edge, which show the perfect plastic nature of H340LAD parent metal. Figures 10(a) and 10(b)) respectively show the tensile curves of two kinds of parent metal (H340 LAD and EN 10 292TL4225). The H340 LAD steel plate obviously shows a better toughness. There are two kinds of equiaxed dimples with different sizes on the EN 10292 TL4225 fracture surface, and the densely small dimples distribute around the big dimples. The larger dimples can not only be formed by small particles (TiN and AIN etc.) in the parent metal, but also can be formed by the accumulation of small dimples. ${ }^{10,11)}$

Figure 9(c) shows the fracture micrograph of the different materials spot welding joint between EN 10292TL4225 and H340 LAD. The expansion of the crack on fracture surface is obviously a mixed mechanism. The typical equiaxed dimple fracture occurs at the side of micro-alloy steel H340LAD. The brittle fracture exists at the side of EN 10292 TL4225 steel plate. The fractograph morphology looks like martensite. It often generates at the fracture surface of some thermal treatment specimens which are directly quenched after being austenitized. ${ }^{12,13)}$ Figure 10(c) shows the tension curve of the different materials spot welding joints between EN 10292TL4225 and H340 LAD. When the stress exceeds the elastic limit, the slope of the tension curve (Fig. 10(c), between a and b) significantly diminish, and the deformation rapidly increase in this stage. The main reason is that yielding occurs at the micro-alloy steel H340LAD side. There is also much plastic deformation except the elastic deformation in this stage. The fracture firstly occurs at the point A zone (as shown in Fig. 9(e)) of the micro-alloy steel H340LAD when added to the maximum load, where small notches are formed and a large amount of stress concentration is generated. Then fracture cracks spread sharply from the A point along the circular nugget to point $\mathrm{B}$ and $\mathrm{C}$, which demonstrates that the frac-

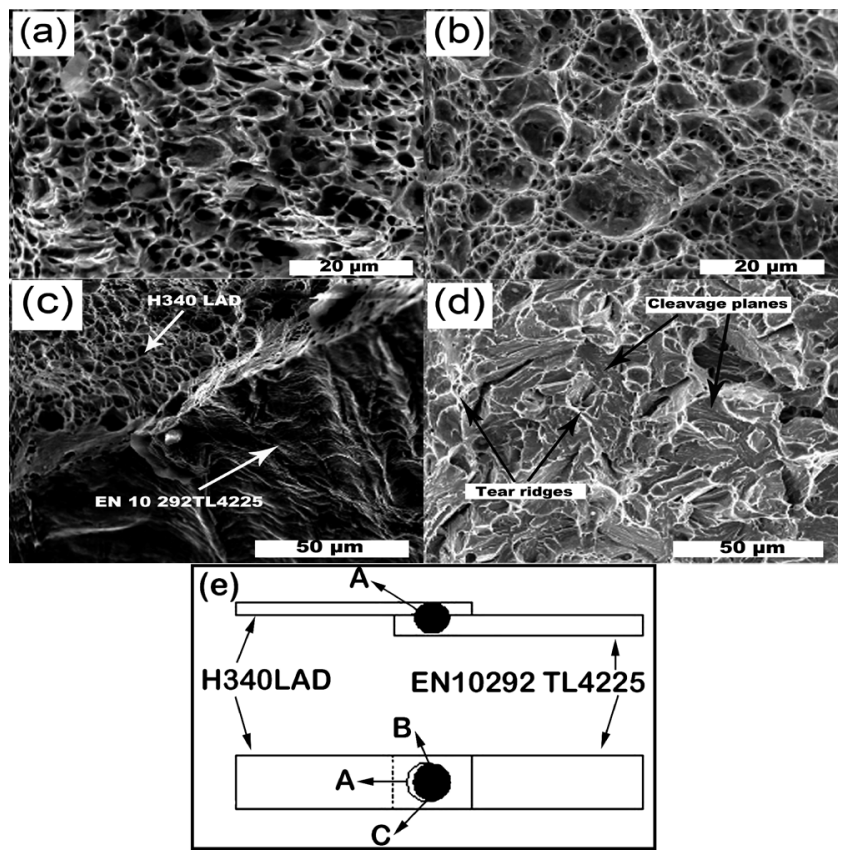

Fig. 9. The scanning electron fractograph and sketch map of fracture process. (a) The H340 LAD parent metal; (b) the EN 10292 TL4225 parent metal; (c) the different material welded joint; (d) the same material welded joint between two EN 10292 TL4225 steel plates; (e) the fracture process of different material welded joints.

ture mechanism change from dimple fracture to intergranular brittle fracture. The intense stress concentration in the small notches is the main factor which results in ductile-tobrittle trasition in the welded joints. Scanning electron fractograph shows that the brittle fracture mode is cleavage. The microstructure of cleavage fracture is characterized by secondary crack and vein pattern.

Figure 9(d) shows the fractograph of similar material (EN 10292 TL4225) welded joints. The fracture mode belongs to quasi-cleavage transgranular fracture, The quasicleavage small planes is not connected according to the second-cleavage mode but a tearing way with larger plastic deformation. From Fig. 9(d) we can see that many tear ridges are generated on the fracture surface, which makes the fracture process have more micro-plastic deformation. Before tension test the specimen length is $215 \mathrm{~mm}$, but the length extends to $222.5 \mathrm{~mm}$ after tension test. The percentage enlongation is about $3.48 \%$. There is an evident plastic deformation before fracture occur, and the cleavage small planes should be generated after the plastic deformation. So the fracture still belongs to toughness. Lath martensite and ferrite are the main microstructure in the fracture zone, and a 

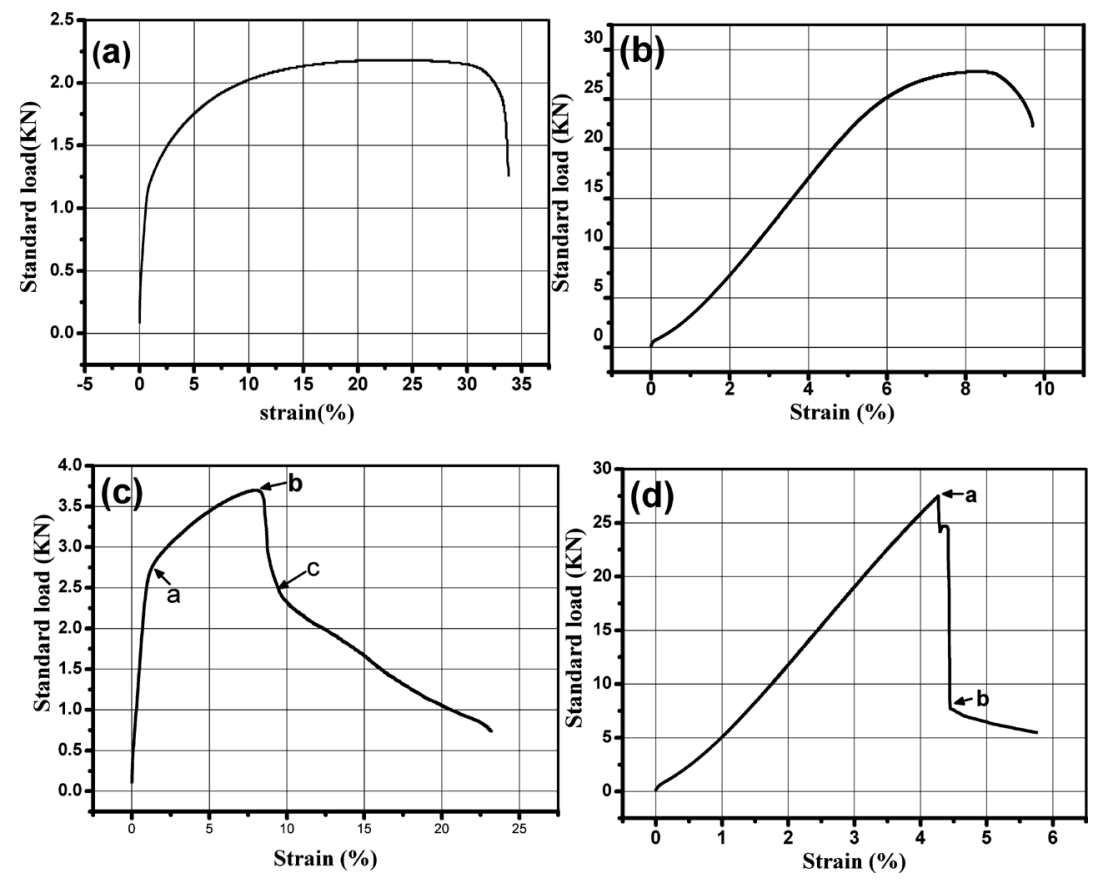

Fig. 10. Tension curves of parent metal and two kinds of welded joints. (a) The H340 LAD parent metal; (b) the EN 10 292TL4225 parent metal; (c) the different material welded joints; (d) the welded joint between two EN 10 292 TL4225 steel plates.

high dislocation-density exists in the lath martensite, which generates huge resistance on the slip of grain. There is a strong interaction between stress and high dislocation density, which could enhance the strength of lath martensite. So the welded joints still have high shear strength. The microstructure of cleavage fracture is characterized by secondary crack and quasi-cleavage small planes.

\section{Conclusions}

(1) The ultra-high strength steel EN 10292 TL4225 has good spot welding performance. When the IF spot welding process and the proper process parameters (preliminary press time: $600 \mathrm{~ms}$, welding time: $350 \mathrm{~ms}$, welding current: $7.5 \mathrm{kA}$, The number of welding pulse: 2, maintain time: $200 \mathrm{~ms}$.) are used, the shear strength of the two kinds of weld joints meet the actual production requirement completely. Moreover, the welded joints have good internal quality, and no internal defects such as crack and shrinkage hole are found.

(2) The microstructure of the welded joints between two EN 10292TL4225 steel plates is also martensite, and the only difference is that the grains of welded joints are a little coarser than those of the original material. The microstructure of the welded joints between EN 10292 TL4225 and H340 LAD is martensite and ferrite.

(3) The fracture fractograph of the welded joints between EN 10292TL4225 and H340 LAD belongs to dimple fracture, but that of the welded joints between EN 10292 TL4225 is cleavage transgranular fracture, and the cleavage planes generate after the plastic deformation. Both of them are toughness fracture.

(4) The Rockwell hardness value is very low at the plastic ring of the welded joints between two EN 10292 TL4225 steel plates. The main reason is that a large amount of ferrite generates at the zone after welding and the hardness is therefore reduced apparently. The hybrid microstructure in the plastic ring zone consists of ferrite and lath martensite.

\section{REFERENCES}

1) K. Mori, S. Saito and S. Maki: Annals-Manufacturing Technology, 57 (2008), 321.

2) A. Turetta, S. Bruschi and A. Ghiotti: J. Mater. Process. Technol., 177 (2006), 396.

3) X. Zhang, G. Chen, Y. Zhang and X. Lai: J. Mater. Process. Technol., (2008).

4) M. Suehiro, J. Maki, K. Kusumi, M. Ohgami and T. Miyakoshi: Nippon Steel Tech. Rep., No. 88, (2003).

5) T. Altan: Stamping Journal, 18 (2006), No. 12.

6) M. Naderi, L. Durrenberger and A. Molinari: Mater. Sci. Eng., 478 (2008), 130.

7) X. Zhu, Z. Ma and L. Wang: Baosteel Technology, 5 (2005), 1.

8) H. J. Wang: Dies Manufacture, 4 (2005), 32.

9) J. Lin, Q. Hu, I. Wangl, W. Bao, X. Lv and H. Tian: Chinese Journal of Construction Machinery, 5 (2007), No. 3.

10) T. B. Hilditch, J. G. Speer and D. K. Matlock: Mater. Des., 28 (2007), 2566.

11) W. S. Owen, E. A. Wilson and T. Bell: The Structure and Properties of Quenched Iron Alloys, in High Strength Materials, ed. by V. F. Zackay, J. Wiley, New York, (1865), 167.

12) A. R. Marder and G. Krauss: Trans. Am. Soc. Met., 60 (1967), 651.

13) G. Krauss and A. R. Marder: Metall. Trans., 2 (1971), 2343. 